\title{
The experiences of parents of children with mental disability regarding access to mental health care
}

\author{
R A Coomer \\ Gender Research and Advocacy Project at the Legal Assistance Centre, Windhoek, Namibia
}

\begin{abstract}
Objective: The aim of this qualitative study was to describe the problems that parents or caregivers of children with mental health disabilities and disorders in Namibia experience when accessing healthcare resources for their children. Method: Data was collected through focus group discussions with the participants and individual interviews with the key informants. Overall, a total of 41 people provided information for this study. Thematic data analysis was used to assess the data. Results: The main barriers experienced by the parents were poor service provision, transport and money, whilst access to education services facilitated access to healthcare services. Conclusion: The challenges go beyond commonly-reported problems such as sub-optimal service provision and include the basic challenge of lack of transportation to reach healthcare services. Many of the barriers identified in this study have been related to general problems with the healthcare system in Namibia. Therefore there is a need to address general concerns about healthcare provision as well as improve specific services for children with mental health disabilities and disorders in Namibia.
\end{abstract}

Keywords: Mental health; Barriers; Namibia; Service provision; Children

Received: $23-06-2012$

Accepted: $20-08-2012$

doi: http://dx.doi.org/10.4314/ajpsy.v16i4.36

\section{Introduction}

The WHO estimates that $20 \%$ of children worldwide are affected by mental health disorders and almost half of all lifetime mental health disorders start by age fourteen. ${ }^{1,2}$ Therefore, addressing mental health disorders in children and adolescents should be an international priority. ${ }^{3,4}$ However, despite contributing to $12 \%$ of the global disease burden, only $1 \%$ of the world health budget is spent on mental health. 5,6

The burden of mental health disorders is highest in developing countries where the greatest proportion of mental health sufferers, but the lowest proportion of services, are found. ${ }^{7}$ Mental healthcare is often sidelined owing to the overwhelming burden of diseases such as HIV/AIDS which take the bulk of healthcare budgets. ${ }^{8}$ The burden of mental health disorders in Africa is in particular is exacerbated by associated factors such as inadequate care at childbirth,

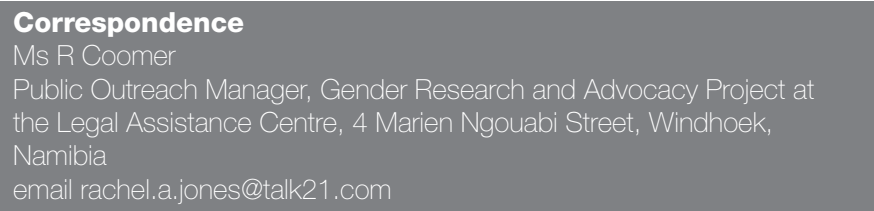

malnutrition, malaria and parasitic diseases, the impact of conflict and civil strife, the increasing impact of alcohol and drug abuse, poverty and natural disasters. ${ }^{9}$

Namibia is one of the many countries across the world struggling to address the needs of children with mental health disabilities and disorders. ${ }^{10}$ Mental health disorders are a major cause of morbidity and mortality in the country. ${ }^{11}$ However, limited data is available on the incidence of mental health disorders and where the data does exist, statistics are often widely variable. 12,13,14,15,16 For example, the 2006 Namibia Inter-Census Demographic Survey reports that only 5\% of people in Namibia have a disability. Of this percentage, 1 1\% are classified as having a mental health disability. The survey does not cite separate data on the incidence of mental health disabilities in children. ${ }^{17}$ In contrast, a 2008 Ministry of Health report estimates that $2.34 \%$ of the population were treated for mental health disorders. ${ }^{18}$ Both estimates suggest that the incidence of mental health disorders in Namibia is lower than the global estimates. ${ }^{19}$ However it is likely that this is due to a lack of recognition of mental health problems rather than a lack of morbidity. The lack of robust data to support the incidence of mental health problems may be one reason for the insufficient provision of and access to mental healthcare services. According to Namibia's Mental Health Policy, the 
government provides a total of 211 psychiatric beds provide for the mental health needs of the entire population and in 2005 the World Health Organisation reported that there were 1.5 psychiatric beds and 0 psychiatric nurses per 10000 population and 0.2 psychiatrists, 6 psychologists, and 6 social workers per 100000 population in Namibia. ${ }^{20,21}$ In 2012 the Health Professions Council of Namibia reported by personal communication that there are 96 registered psychologists to serve a population of 2.1 million - which is equivalent to 4.6 psychologists per 100000 of the population, suggesting that service provision is in fact decreasing. The Council was not able to provide data on the number of registered psychiatric nurses. However, psychiatry is one of the major subjects in the nursing diploma/degree most of the 5600 registered nurses in Namibia are trained in psychiatry.

Whilst there is limited data available on the incidence of adult mental health disabilities and disorders in Namibia, there is even less information on the incidence of child mental health disabilities and disorders. Only three peer-reviewed studies have assessed the mental health needs of children in Namibia and these studies do not provide population-based data. ${ }^{22,23,24}$ This is despite the fact that a national representative study to assess the living conditions of people with disabilities reported that almost half the respondents stated that the onset of their disability took place before the age of five. ${ }^{25}$

Data from neighbouring South Africa, a country which shares many social and historical similarities with Namibia, shows that there is a high level of unmet need in South Africa. ${ }^{26}$ For example, the South African Stress and Health (SASH) study, the first large-scale population-based study of common mental disorders conducted in South Africa, showed an adult prevalence of $30.3 \%$ and only $25.2 \%$ of the people with a mental health diagnosis had sought treatment within the previous 12 month. ${ }^{27}$

The purpose of this study was to explore the challenges parents/caregivers of children with mental health disabilities and disorders in Namibia face when attempting to access mental healthcare resources in an effort to provide more information in a poorly researched area.

\section{Method}

\section{Design}

The study used a qualitative exploratory design to identify the extent to which children with mental health challenges are able to access healthcare resources. Due to resource limitations, the study was only conducted in Windhoek, the capital of Namibia.

\section{Sample}

Purposive sampling was used to recruit participants to the study. Contact was made with two schools for children with mental health disabilities and disorders in Windhoek. The Principals granted permission for data to be collected at the schools and assisted with the identification of participants. Contact was also made with a volunteer from the organisation "Special Needs Network" who granted permission for researcher to collect data from beneficiaries of the network.

\section{Ethics}

The study was approved by the University of the Western Cape's Senate Research and Ethics Committee.

\section{Data}

Data was collected through focus group discussions. The methodology of focus group discussions was chosen because it allows for participant interaction and the development of group opinion. ${ }^{28}$ Group discussions are particularly useful to identify common experiences or to access a range of viewpoints about a situation and are extremely dynamic when administered correctly. 29,30

The use of focus groups as a means of data collection is a common methodology in the field of mental health research. For example, focus group discussions have been frequently used by the Mental Health and Poverty Project (MHaPP) to collect data. ${ }^{31,32,33,34}$ Focus group discussions have also been used by other researchers to assess mental health needs in a variety of contexts. ${ }^{35,36,37,38,39,40}$ The ability to speak English to a fair standard was a requirement to participate in the study.

Open-ended semi-structured questions were used to collected data. Each focus group followed the same structure although the order of the topics discussed and the number of questions debated was dependant on the dynamics within the group and the time available. In general, the majority of questions were discussed by all groups. A summary of the topics discussed is shown below:

1. Understanding the concept of mental health, mental illness and associated stigma and discrimination

2. Access to services

3. Barriers to services

4. Principles of service provision such as confidentiality and informed consent

5. Recommendations for service provision

The focus group discussions were supplemented by interviews with key informants. Data analysis was achieved through transcription of the data followed by coding and thematic analysis of the grouped data.

\section{Results}

Three focus groups were conducted. The majority of participants were parents and caregivers of children who have mental health disabilities and disorders. Some teachers and support staff from the schools where the focus group discussions were held also participated in the discussions. Twelve participants ( 11 females and 1 male) attended the first focus group, eight participants ( 7 females and 1 male) attended the second focus group and seventeen participants (13 females and 4 males) attended the third focus group. Four key informants were interviewed; two were parents of children with mental health disabilities/disorders. The other two key informants were the principals of the schools where the focus group discussions were held. To protect confidentiality, the key informants are described as key informant 1-4 and of female gender although they were of both sexes.

The participants were from a range of cultural groups. The participants were not requested to identify their cultural group as no responses indicated this information was relevant to the research. Overall, a total of 41 people provided information for this study. 
Analysis of the discussions resulted in the identification of the following themes:

1. Poor service provision, in particular language barriers and need for therapeutic services

2. Lack of transport as a barrier to accessing healthcare services

3. Lack of money to pay for healthcare services

4. The importance of educational services for accessing healthcare services

\section{Poor service provision, in particular language barriers and need for therapeutic services}

Many of the participants stated that they receive poor service provision. Nurses were commonly cited as providing poor service and being rude or difficult when dealing with children with mental health disorders. The participants in the first focus group stated that they do not see the same healthcare specialists on a regular basis - as one participant said, "there is too much change with doctors, you have to keep restarting to tell your story". One of the participants described the experience at the hospital as "stressful" as the doctors are not always available and the parents have to make repeated trips in order to have a consultation. This means that the child has to keep missing school and the parent has to get sick notes each time to explain the absence of the child. Another participant stated that "my experience every time is that service at the clinic and hospital is very poor. It is the same for the elderly and the very sick"'. The participants in the second focus group discussion also criticised healthcare services for not providing enough support or advice on treatment options. The participants complained that the doctors "do not have knowledge" and "do not know what might be in the best interests of the child, such as whether swimming will help, or occupational therapy". The participants complained that there is a "lack of expertise" and that as soon a doctor makes a diagnosis, he/she will give a prescription and end the consultation rather than providing any further support or information.

The participants in the third focus group discussion made similar points stating that the doctors are not "treating the cause of the sickness". One participant said the doctors are just "prescribing pills and not giving other treatments". The participants also complained that they are often only prescribed painkillers or medication to make the child sleepy rather than being provided with specific medication for the condition. (The problem of being prescribed painkillers is not limited to mental healthcare problems, but rather seems to be a common treatment option by state healthcare providers, perhaps because state hospitals have limited prescription options and off-patent painkillers are cheap and can provide some symptomatic relief, or because the doctors do not have sufficient time or specific expertise to review cases to determine what better medication could be provided). Lack of time does appear to be a problem as the participants also stated that the children may not even be seen by a doctor, instead being seen by student nurses, who can only provide limited therapeutic options, such as painkillers. One of the participants complained about the lack of counselling services, explaining that counselling would be much more helpful than taking painkillers. The repeated reference to the prescription of painkillers, which was discussed in all groups, suggests that the problem is commonly experienced. This suggests that some doctors and nurses do not engage with the patient's condition and seem to give broad treatments for symptoms rather than dealing with the core problems. This may be caused by insufficient training on mental health conditions or the fact that the doctor is only seeing the patient for a single visit and is not experienced with the clinical history of the child.

Many participants cited languages barriers between themselves and the service providers. The participants explained that the doctors may be unwilling to speak to the parents/caregivers in their indigenous language, even if they are able to speak the language.

All of the participants stated that parents will access private care if possible, although they noted that for most people this is not an option owing to lack of money. However, one of the key informants did identify problems with service provision from a medical aid provider in the form of stigma and discriminatory financial aid (the medical aid provider was unwilling to provide equivalent financial support for a mental health condition compared with a physical condition).

\section{Lack of transport as a barrier to accessing healthcare services} The participants in all focus groups stated that lack of affordable transport to the hospitals is a problem. The participants complained that they do not have the money to pay for the taxi fares needed to visit the hospital. Although the families live relatively close to the hospital (for example within $5 \mathrm{kms}$ ), the participants explained that travelling on foot with a child with a mental health disability can be extremely difficult even over a short distance. When the child also has a physical disability, travelling on foot can be impossible. The average cost of a return trip for the participants was just N\$16 (US\$1.9).

The participants in the first focus group discussion explained that if they do not have the money to pay for a taxi between the clinic and the hospital, they may be taken to the hospital in an ambulance. Whilst this does mean that the family is able to access healthcare services, it there is still a delay between the time the parents need to access healthcare services for their children and when they are able to as they often have to wait for an ambulance. It also means that emergency services are being reallocated from their designated function, which could cause problems in situations when ambulances must respond to accidents whilst transporting non-critical patients.

The broader context of the discussions revealed that the reason the cost of transport is such a barrier is because of the poor service provision the families receive, as discussed above. The fact that the service provision is so poor makes the cost: benefit ratio of paying for the transport to the hospital too high.

\section{Lack of money to pay for healthcare services}

The participants in all focus groups also stated that the cost of healthcare is a barrier, even when accessed through the state healthcare system. The participants stated that they are required to pay N\$15 (US\$1.8) for a hospital consultation (the standard fee in Namibia) even though children with disabilities should be exempt from these fees. The participants did not know how to get an exemption, or what information was required. Key informant four made similar comments, saying that money can be a problem as parents may not be able to afford the consultation fee or cannot afford to take a child for any follow-up appointments that are needed. 
The participants in two of the focus groups discussed access to the government grant for children with disabilities. The participants in both groups stated that it is hard to access. The participants in the first focus group discussion were positive about the help the grant provides but noted that the amount paid was small. One of the participants explained that it can take approximately three months to access the grant, and with the time and transport required to access it, it can mean that when the grant is finally released, the first few payments may be used to pay back money borrowed to access the grant. The participants in the second focus group discussion were more negative about the grant and felt that it was difficult to access.

\section{The importance of educational services}

Even though the researcher used a range of questioning probes to obtain details on healthcare services with the groups, the participants had less information to share about healthcare services compared to other services, such as education. Key informant two also stated that the school provided the best support for the child and the family. This suggests that for many of the participants, access to education is a greater priority than access to healthcare. One of the reasons appears to be because the schools help to facilitate access to healthcare services. The interviews with the two principals showed that the schools are dedicated to trying to ensure that the children receive the healthcare services they need. The principals also cited a number of examples where they had to intervene on behalf of the parents to ensure that the correct care was provided

\section{Discussion}

Poor service provision was a recurring theme in this study. The government of Namibia has noted problems with service delivery within this sector as well as more broadly.41,42 Therefore whilst it is undoubtedly true that more must be done to improve the quality of mental health service provision, more must be done in general to improve the quality of healthcare services in Namibia. Language barriers were identified as a sub-theme of poor service provision. The problem of language as a barrier in Namibia has not been reported as a general barrier to healthcare. However, it is unlikely that it is a problem that is specific to the treatment of mental health conditions but is rather a global issues that must be addressed. Therefore this research identifies new findings as well as highlighting continuing problems with the healthcare system.

It should be noted that whilst the participants in this study had very negative opinions about service delivery, some progress is being made to improve access. For example, a Sister working at the Central Hospital Mental Health Unit, briefly interviewed by telephone after the focus group discussions and key informant interviews were conducted, stated that the Unit conducts outreach visits to clinics in Katutura and others areas of Windhoek to see mental health patients on a weekly basis. It is likely that the patients who receive help through these means experience better service delivery. Yet it is clear that the need for these services is much greater than the resources available as the participants in this study who are also resident in Windhoek did not mention such outreach programmes, suggesting that they do not benefit from them.

The participants all lived in urban areas in relatively close proximity to the hospitals where they accessed mental health services, but they still found transport to be a barrier, mainly as a result of poverty. The problem of transport has not been commonly reported as a barrier to mental healthcare in the literature, although the problem has been recognised in rural Australia. ${ }^{43}$ However transport has been identified as a general barrier to accessing healthcare services in Namibia -according to the national health and demographic survey, $41.7 \%$ of people find it to be a problem. ${ }^{44}$ Distance to healthcare services has also been identified as a general barrier to accessing healthcare services. ${ }^{45}$ This study provides further evidence to motivate better access to services in Namibia.

Although the participants stated that they experienced problems travelling in Windhoek, the City of Windhoek does make provision for people with disabilities to travel for free on municipal buses. On questioning, the Municipality did not report receiving complaints from people with disabilities about the service. The discrepancy between the experience of the parents and the service provided by the City of Windhoek suggests that there is a lack of awareness about the transport option and the City of Windhoek should do more to ensure that people are aware of this service. There is also a need to involve private organisations such as Namibia Bus and Taxi Association to increase awareness about mental health disabilities and disorders amongst private transport services providers.

The impact of poverty on mental health is well known. ${ }^{46,47}$ This study provides further evidence of this linkage and provides new information about the extent that poverty impacts on mental health - as noted above, for many of the participants in the study paying the taxi fare or admission fee at the hospital (each less than US\$2) is too much of a barrier to access services. Data for Namibia shows that although the country is classed as a middle-upper economically developing country, Namibia has one of the highest Gini Co-efficients in the world, which means that for many people there is little money for anything other than the basic necessities needed to survive. ${ }^{48}$

The government has made provision for children with disabilities to be exempt from the administration fee. ${ }^{49}$ However it appears to be that this information has not been effectively disseminated to the public, and front line service providers do not seem to proactively inform the public about the exemption.

The government also provides a disability grant, however many participants said that it hard to access the grant due to the time it takes to register and the logistical costs (such as travel to the government offices) involved during the process. Data from the Ministry of Gender Equality and Child Welfare shows that only 1821 disability grants were dispersed in 2010 despite the fact that there are 33,614 children with disabilities enrolled in the education system. ${ }^{50,51}$ The complaints from the participants provide an explanation as to why access may be so low. The low disbursement of grants is a matter of concern as research in Namibia has shown that even though grant amounts are small, they can play an important role in alleviating poverty. ${ }^{52}$

The problems of lack of money and transport as barriers to healthcare services show how mental health challenges in Namibia are considered the responsibility of the family with little support from the government. The isolation of families who have children with disabilities has been previously noted in the context of children with disabilities not attending school. ${ }^{53}$ Whilst international recommendations support the decentralisation of mental health care with a focus on care in the community ${ }^{54}$, this does not negate the role of the government to provide support to families with children who have mental health disabilities and disorders. 
Whilst money and transport are barriers to accessing healthcare services, this study identified the importance of educational services as a means of promoting access to healthcare services. For many of the participants, the support provided through the education system is the most effective and vital service they receive. However, whilst this is a positive finding it is also a matter of concern because evidence suggests that many children with disabilities are not accessing educational services ${ }^{55}$, and these children are not receiving help and so have access to a much narrower range of healthcare services. Furthermore, the children of the participants in this study attended two specialist schools that have better access to services, such as regular visits from specialist nurses and therapists than most mainstream schools will have. Whilst the government is starting to do more to realise the concept of inclusive education through the development of a policy on this matter, the concept is not yet fully integrated into the educational system and many children with mental health disabilities remain outside of the system.

There are a number of recommendations that can be made based on the results of this study. For example, as recommended by the World Health Organisation, the government should focus on the decentralisation of mental health services into primary care. ${ }^{56}$ This will circumvent the problems that money and lack of transport play in accessing hospital-based healthcare services. The government should also ensure that the public is aware of cost exemptions that are available including free transport on municipal buses and waiver of the hospital admission fee.

Non-governmental organisations also have a role in supplementing these initiatives by holding government to account to better provide services for the treatment of mental health conditions as well as to ensure that the public are aware of their rights in terms of accessing healthcare, and through providing therapeutic services that cannot always be obtained through the state healthcare system. Given that many of the problems identified in this study are not unique to Namibia, service providers and community activists should also look to neighbouring countries to see how such problems are being addressed. Civil society organisations in Namibia that do not currently work much in the field of mental health could also build partnerships with organisations from other countries to provide resources and assistance to people with mental health challenges without the need to develop initiatives from scratch.

\section{Limitations of the study}

Due to time and financial constraints this study was only conducted with a small group of people in the capital of Namibia. There is a clear need to upscale the research to other areas across the country. Another limiting factor is that to protect confidentiality, details of the age of the children and their mental health conditions were not recorded. Therefore this information cannot be used as a lens with which to review the results.

\section{Conclusion}

This study shows that parents of children with mental health disabilities and disorders experience a number of barriers that hinder access to healthcare services. The challenges go beyond commonly-reported problems such as sub-optimal service provision and include the basic challenge of lack of transportation to reach healthcare services.
Many of the barriers identified in this study have been related to general problems with the healthcare system in Namibia. Therefore there is a need to address general concerns about healthcare provision as well as improve specific services for children with mental health disabilities and disorders in Namibia.

\section{Acknowledgement}

The data was part of a Masters degree (MA) completed by the author at the University of the Western Cape.

\section{References}

1. World Health Organization. Mental health atlas 2005. Geneva, Switzerland: World Health Organisation, 2005.

2. Kessler RC, Berglund P, Demler O, Jin R., Merikangas KR, Walters EE. Lifetime prevalence and age-of-onset distributions of DSM-IV disorders in the National Comorbidity Survey Replication. Archives of General Psychiatry 2005; 62:593-602.

3. World Health Organization. Mental Health: New Understanding, New Hope. Geneva, Switzerland: World Health Organisation, 2001.

4. World Health Organization. Child and adolescent mental health resources atlas. Global concerns: implications for the future. Geneva, Switzerland: World Health Organisation, 2005.

5. World Health Organization. Caring for children and adolescents with mental health disorders. Geneva, Switzerland: World Health Organisation, 2003.

6. World Health Organization. mhGAP Mental Health Gap Action Programme. Scaling up care for mental, neurological, and substance use disorder. Geneva, Switzerland: World Health Organisation, 2008.

7. Patel V. Alcohol use and mental health in developing countries. Annals of Epidemiology 2007;17(5; Supplement):S87-S92.

8. World Health Organization. Child and adolescent mental health resources atlas. Global concerns: implications for the future. Geneva, Switzerland: World Health Organisation, 2005.

9. Okasha A. Mental health in Africa: the role of the WPA. World Psychiatry 2002; 1 (1):32-35.

10. World Health Organization. Child and adolescent mental health resources atlas. Global concerns: implications for the future. Geneva, Switzerland: World Health Organisation, 2005.

11. Ministry of Health and Social Services. Health and Social Services System Review. Windhoek, Namibia: Ministry of Health and Social Services, 2008.

12. National Planning Commission. 2001 Namibia Population and Housing Census. Windhoek, Namibia: National Planning Commission, 2001.

13. National Planning Commission. 2006 Namibia Inter-censal Demographic Survey. Windhoek, Namibia, National Planning Commission, 2010.

14. National Planning Commission. Children and adolescents in Namibia. Windhoek, Namibia: National Planning Commission, 2010.

15. Ministry of Health and Social Services. Health and Social Services System Review. Windhoek, Namibia: Ministry of Health and Social Services, 2008.

16. Ministry of Health and Social Services. National Mental Health Policy. Windhoek, Namibia: Ministry of Health and Social Services, 2005.

17. National Planning Commission. 2006 Namibia Inter-censal Demographic Survey. Windhoek, Namibia, National Planning Commission, 2010.

18. Ministry of Health and Social Services. Health and Social Services System Review. Windhoek, Namibia: Ministry of Health and Social Services, 2008.

19. World Health Organization. Mental health atlas 2005. Geneva, 
Switzerland: World Health Organisation, 2005

20. Ministry of Health and Social Services. National Mental Health Policy. Windhoek, Namibia: Ministry of Health and Social Services, 2005

21. World Health Organization. Mental health atlas 2005. Geneva, Switzerland: World Health Organisation, 2005.

22. Brown DW, Riley L, Butchart A, Meddings DR., Kannb L, \& Harveya AP. Exposure to physical and sexual violence and adverse health behaviours in African children: Results from the Global School-based Student Health Survey. Bulletin of the World Health Organization 2009; 87:447-455.

23. Page RM, Hall CP. Psychosocial distress and alcohol use as factors in adolescent sexual behavior among Sub-Saharan African adolescents. Journal of School Health 2009; 79 (8):369-379.

24. Ruiz-Casares $M$, Thombs BD, Rousseau C. The association of single and double orphanhood with symptoms of depression among children and adolescents in Namibia. European Child and Adolescent Psychiatry 2009; 18(6):369-376.

25. Eide AH, van Rooy G Loeb, ME. Living conditions among people with activity limitations in Namibia. A representative, National survey. Oslo, Norway: SINTEF, 2003.

26. Seedat S, Williams DR., Herman AA, Moomal H, Williams SL, Jackson $P B$ et al. Mental health service use among South Africans for mood, anxiety and substance use disorders. South African Medical Journal 2009; 99:346-352.

27. Herman AA, Stein DJ, Seedat S, Heeringa SG, Moomal H, Williams DR The South African Stress and Health (SASH) study: 12-month and lifetime prevalence of common mental disorders. South African Medical Journal 2009; 99:339-344.

28. Wong LP. Focus group discussion: A tool for health and medical research. Singapore Medical Journal 2008; 49 (3):256-261.

29. Gilbert N. Researching Social Life. 3rd edition. London, United Kingdom: Sage Publications Limited, 2008

30. Berg BL. Qualitative Research Methods for the Social Sciences (4th Ed.). Boston, Massachusetts: Allyn \& Bacon, 2007.

31. Ofori-Attal A, Read UM, Lund C, \& the Mental Health and Poverty Project Research Programme Consortium. A situation analysis of mental health services and legislation in Ghana: challenges for transformation. African Journal of Psychiatry 2010; 13: 99-108.

32. Akpalu B, Lund C, Doku V, Ofori-Atta A, Osei A, Ae-Ngibisel K, et al. Scaling up community-based services and improving quality of care in the state psychiatric hospitals: the way forward for Ghana. African Journal of Psychiatry 2010; 13:109-115.

33. Kleintjes S, Lund C, Swartz L, Flisher A, \& the Mental Health and Poverty Project Research Programme Consortium. Mental health care user participation in mental health policy development and implementation in South Africa. International Review of Psychiatry 2010; 22(6):568-577.

34. Ssebunnya J, Kigozi F, Lund C, Kizza D, Okello E. Stakeholder perceptions of mental health stigma and poverty in Uganda. BMC International Health and Human Rights 2009; 9:5 doi:10.1186/1472698X 95

35. Barrio, C., Palinkas, L.A., Yamada, A., Fuentes, D., Criado, V., Garcia, $P$. et al. Unmet needs for mental health services for latino older adults: Perspectives from consumers, family members, advocates, and service providers. Community Mental Health Journal 2008; 44(1): 57-74

36. Gibbss SM, Brown MJ, Muir WJ. The experiences of adults with intellectual disabilities and their carers in general hospitals: A focus group study. Journal of Intellectual Disability Research 2008; 52(12):1061-1077.

37. Palinkas LA, Criado V, Fuentes D, Shepherd S, Milian H, Folsom D, et al.
Unmet needs for services for older adults with mental illness: comparison of views of different stakeholder groups. American Journal of Geriatric Psychiatry 2007; 15(6):530-540.

38. Schulze BA, Angermeyer MC. Subjective experiences of stigma. A focus group study of schizophrenic patients, their relatives and mental health professionals. Social Science and Medicine 2003; 56(299):299-312.

39. Shattell MM, Hamilton D, Starr SS, Jenkins CJ, Hinderliter NA. Mental health service needs of a Latino population: A community-based participatory research project. Issues in Mental Health Nursing,2008; 29:349-368

40. Wong YI, Sands RG, Solomon PL. Conceptualizing community: The experience of mental health consumers. Qualitative Health Research 2010; 1-14. DOI: 10.1177/1049732310361610

41. Ministry of Health and Social Services. National Mental Health Policy. Windhoek, Namibia: Ministry of Health and Social Services, 2005.

42. Ministry of Health and Social Services. Health and Social Services System Review. Windhoek, Namibia: Ministry of Health and Social Services, 2008.

43. Kurtin M, Barton C, Winefield A, Edwards J. What are the mental health needs of adolescents in rural South Australia? The perceptions of human service providers. Australasian Medical Journal 2009; 1(6): 1-33.

44. Ministry of Health and Social Services. Namibian Demographic and Health Survey 2006-07. Windhoek, Namibia: Ministry of Health and Social Services, 2008.

45. Ministry of Health and Social Services. Health and Social Services System Review. Windhoek, Namibia: Ministry of Health and Social Services, 2008.

46. Lund C, Breen A, Flisher AJ, Kakuma R, Corrigall J, Joska JA, et al. Poverty and common mental disorders in low and middle income countries: A systematic review. Social Science and Medicine 2010;71:517-528.

47. Patel V, Kleinman A. Poverty and common mental disorders in developing countries. Bulletin of The World Health Organization 2003;81 (8):609-615.

48. United Nations Development Programme (UNDP). Human Development Report 2009. Overcoming barriers: Human mobility and development. New York, United States of America: United Nations Development Programme, 2009.

49. Hospitals and Health Facilities Act of 1994. Government Gazette 4459.

50. Ministry of Gender Equality and Child Welfare. Disability grants by year. Data obtained by request through the Ministry's website http://www.namchild.gov.nal. 2010.

51. Education Management Information System (EMIS). Education statistics 2009. Windhoek, Namibia: Ministry of Education, 2008 Table 61

52. Levine S, van der Berg S, Yu D. The impact of cash transfers on household welfare in Namibia. Development Southern Africa 201 1, 28(1):39-59.

53. Lopez Levers L. Examining northern Namibian teachers' impressions of the effects of violence, gender, disability, and poverty on young children's development: school-based countermeasures. Journal of Children and Poverty 2002;8(2):101-140.

54. World Health Organization. Mental Health: New Understanding, New Hope. Geneva, Switzerland: World Health Organisation, 2001.

55. Lang R. Disability policy audit in Namibia, Swaziland, Malawi and Mozambique. London, United Kingdom: The Leonard Cheshire Disability and Inclusive Development Centre, 2008.

56. World Health Organization. Mental Health: New Understanding, New Hope. Geneva, Switzerland: World Health Organisation, 2001 